INTERNATIONAL JOURNAL OF SCIENTIFIC RESEARCH

\title{
COMPARATIVE ANALYSIS OF NON-DESCENT VAGINAL HYSTERECTOMY VERSUSTOTAL ABDOMINAL HYSTERECTOMY IN BENIGN UTERINE DISORDERS AT DMCH, LAHERIASARAI, BIHAR
}

\section{Gynaecology}

Dr. Suchandra

Dr. Renu Jha*
MBBS, M.S. (Obs. \&Gynae.), Senior Resident, Department of Obstetrics and Gynaecology, Darbhanga Medical College \& Hospital, Laheriasarai, Darbhanga, Bihar. of Obstetrics and Gynaecology, Darbhanga Medical College \& Hospital, Laheriasarai, Darbhanga, Bihar. *Corresponding Author

Dr. [Prof.] Kumudini Jha

MBBS, M.D. (Obs. \&Gynae.), Ph.D. (Obs. \& Gynae.), D.N.B.,Professor and Head of Department, Department of Obstetrics and Gynaecology, Darbhanga Medical College \& Hospital, Laheriasarai, Darbhanga, Bihar.

\section{Dr. Debarshi Jana}

Young Scientist (DST) Institute of Post-Graduate Medical Education and Research, A.J.C. Bose Road, Kolkata-700020, West Bengal, India.

\section{ABSTRACT}

\section{Background: Hysterectomy is the most common operation performed by gynecologist, next to caesarean section.}

Currently, there are three main types of hysterectomy operations in practice for benign diseases-Abdominal hysterectomy (AH), vaginal hysterectomy $(\mathrm{VH})$ and Laparoscopic hysterectomy $(\mathrm{LH})$. Vaginal route for non-descentuterus is an acceptable method of hysterectomy. The objective of present study was to compare the operating time, intraoperative and postoperative complications between VH and TAH in non-descent uterus.

Methods: The study was conducted in the Department of Obstetrics Gynaecology for a period of 18months at Darbhanga Medical College \& Hospital, Laheriasarai, Bihar.

Results: Over the study period 100 patients were taken, 50 patients underwent non-descent vaginal hysterectomy andlabelled as group A and 50 patients were under went total abdominal hysterectomy and labelled as group B. It wasseen that intraoperative complications and postoperative complications were less in group A patients and operating time is also less with group A patients when compared with group B patients.

Conclusions: From the present study, it was concluded that NDVH is associated with less blood loss during surgery, quicker recovery, and early mobilization, less operative and less postoperative morbidity when compared to TAH.

NDVH is a less invasive technique with shorter hospital stay and faster convalescence.

\section{KEYWORDS}

Hysterectomy, Non-descent vaginal hysterectomy

\section{INTRODUCTION}

Hysterectomy is the most common operation performedby gynaecologist, next to caesarean section.

The firstabdominal hysterectomy was performed by Charles clayin Manchester in 1843. Vaginal hysterectomy dates toancient times. Advances in anaesthesia, transfusionservices, surgical techniques and availability ofantibiotics led to hysterectomy becoming the mostcommon non-pregnancy related major surgical procedurein women.

Factors that may influence the route ofhysterectomy for benign causes include the size andshape of the vagina and uterus; accessibility to the uterus; extent of extra uterine disease; the need for concurrentprocedures; surgeon training and experience; availablehospital technology, devices and support; emergency orscheduled cases; and preference of the informed patient.

Currently, there are three main types of hysterectomyoperations in practice for benign diseases-Abdominalhysterectomy (AH), vaginal hysterectomy $(\mathrm{VH})$ andLaparoscopic hysterectomy $(\mathrm{LH})$. AH remains thepredominant method of uterine removal. This route isused for malignancies, bulky uteri or when there areadhesions and removal of uterus is not possible throughvaginal route

Overall mortality rates for $\mathrm{AH}$ or $\mathrm{VH}$ are $0.1-0.2 \%$.

Vaginal route for non-descent uterus is aacceptable method of hysterectomy despite previousbelief that it is the contraindication in certain conditions.

Vaginal route of hysterectomy has distinct health andeconomic benefits in terms of fewer morbidities, betterpostoperative quality -oflife outcomes, reduced hospitalstay and better patient satisfaction.

A Cochrane reviewof 34 randomized trials of abdominal, laparoscopic andvaginal hysterectomy, including 4,495 patients,concluded that vaginal hysterectomy has the bestoutcomes of these three routes. Cost analysis hasconsistently demonstrated that vaginal hysterectomy isthe most cost-effective route.

\section{AIM OFTHE STUDY}

This study was undertakento evaluate the appropriate route of hysterectomy(abdominal/vaginal) in the Obstetrics and Gynaecology department of DMCH.

\section{MATERIALAND METHODS}

One hundred patients whorequired hysterectomy for conditions other than uterineprolapse were included in the study. Of those 100patients, 50 females who were subjected to vaginalhysterectomy were assigned as group A. The remaining50 females who underwent abdominal hysterectomy weretaken as group B. Indications for TAH were uterus size greaterthan 12 weeks, endometriosis, PID, presence of adnexalmass, unexplained pelvic pain, suspected malignancy.

Indications for $\mathrm{VH}$ were uterine size less than 12 weeks, dysfunctional uterine bleeding, quality adenomyosis,chronic PID. Detailed history was taken and thoroughphysical examination was done in all cases admitted forhysterectomy. Written and informed consent was takenfrom the patient for evaluation. All the patients includedin the study were subjected to detailed history andclinical examination including both general physical andsystemic.

All the patients received prophylactic antibioticCefotaxime 1gm intravenously after sensitivity testingone hour prior to surgery. The main parameters used forcomparison in two groups were: duration of surgery,intraoperative blood loss, intraoperative injury if any wasnoted, ambulation, post-operative $\mathrm{Hb}$, fever, woundinfection, postoperative pain, any evidence of infection,duration of hospital stay, follow-up.

\section{RESULTS}

A total of 100 patients were included in the study. Fiftypatient underwent vaginal hysterectomy and 50 patientsunderwent abdominal hysterectomy. Baselinedemographic characteristics were comparable 
in bothabdominal and vaginal hysterectomy groups. None of the patients in the vaginal group had previouspelvic surgeries while one patient in the abdominal grouphad history of one pelvic surgery (e.g tubal ligation,ovarian cystectomy or laparotomy). Thediseases in each group were comparable. In group A, themost common indication for NDVH was DUB (56\%) andin group B, the most common indication was fibroid(66\%). None of the cases in the vaginal groupwere converted to abdominal route.

There were no intraoperative complications such asbladder, rectum or urethra injuries or re-laparotomies inany groups. The mean duration of surgery was 48.6 minutes in the vaginal group, whereas, it was 68.2 minutes in the abdominal group, implying a significantdifference $(\mathrm{p}<0.05)$. Similarly, a significantly higherblood loss $(247.7 \mathrm{ml})$ was noted in the abdominalhysterectomy group, compared to $189.1 \mathrm{ml}$ in the vaginalgroup $(\mathrm{p}<0.05)$.

Postoperatively, the abdominal group required moreanalgesia in comparison to the vaginal group. The meanlength of hospital stay was 7.1 days in the abdominalgroup while the duration was 3.1 days in the vaginalgroup. Mean time to postoperative mobility and meanmaximum postoperative body temperature in the vaginalhysterectomy group were significantly shorter and lesssevere respectively than those in the abdominal group $(\mathrm{p}<0.05)$

Significantly lesser number of patients requiredpostoperative blood transfusion in the vaginal groupcompared to the abdominal group. Significantly highpostoperative wound infection rate in $7 \%$ patients of theabdominal group, compared to the vaginal group $(n=0)$.

However, there was no significant difference in the ratesof systemic infection like respiratory tract infection,urinary tract infection, paralytic ileus and acutegastroenteritis postoperatively in both the groups.

Distribution according to the age group

\begin{tabular}{|l|l|l|}
\hline Age group (yrs.) & $\begin{array}{l}\text { Group A } \\
\text { (No. of Patients) }\end{array}$ & $\begin{array}{l}\text { Group B } \\
\text { (No. of Patients) }\end{array}$ \\
\hline $36-40$ & 2 & 3 \\
\hline $41-45$ & 22 & 28 \\
\hline $46-50$ & 20 & 17 \\
\hline$>50$ & 6 & 2 \\
\hline Total & 50 & 50 \\
\hline
\end{tabular}

Distribution according to the indications of hysterectomy

\begin{tabular}{|l|l|l|}
\hline Indications & Group A & Group B \\
\hline Fibroid & $4(8 \%)$ & $33(66 \%)$ \\
\hline DUB & $28(56 \%)$ & $13(26 \%)$ \\
\hline Adenomyosis & $2(4 \%)$ & $1(2 \%)$ \\
\hline Adnexal mass & $0(0 \%)$ & $2(4 \%)$ \\
\hline Chronic cervicitis & $11(22 \%)$ & $0(0 \%)$ \\
\hline Endometrial hyperplasia & $5(10 \%)$ & $1(2 \%)$ \\
\hline
\end{tabular}

\section{DISCUSSION}

It is well known fact that $70-80 \%$ of hysterectomies donefor benign condition are through abdominal route.

Vaginal hysterectomies are usually performed forprolapsed case.

With adequate vaginal access andtechnical skill, good uterine mobility vaginalhysterectomy can easily be achieved. The main supportsof the uterus, the uterosacral and cardinal ligamentssituated in close proximity to vaginal vault can be easilydivided to produce descent.

Multiparity, lax tissue dueto poor involution following multiple deliveries andlesser tensile strength afford a lot of comfort to vaginalsurgeon even in presence of significant uterineenlargement. In our study, almost eighty five percent ofthe patients had parity of more than equal to three in boththe groups and size of the uterus above 10 weeks was $44 \%$. We could remove uterus up to 14 weeks pregnancysize vaginally without any increase in surgicalcomplication. Banarsee Bhadra et al and Saha $\mathrm{R}$ et al were also able to remove uteri vaginally of the size of $>10$ weeks in their studies.

In present study, most of the patients were in the agegroup of 41-50 years of age $(44 \%)$ and were multipara,which were compatible with Kovac S, Dewan Rupali et alstudy.
The commonest indication for vaginalhysterectomy in non-descent cases was DUB followed byfibroid uterus and adenomyosis which was also compatible with Banarsee Bhadra et al study.

In thisstudy, most of the non-descent vaginal hysterectomyneeded 48.6 minutes, comparatively faster operatingtechnique resulted in shorter hospital stay and less postoperative morbidity as has been reported in comparisonto TAH and present results were compatible with PradeepKumar et al.

In present study, it was observed that one case of vaginalvault frank infection was noted in group A whereas 7patients with frank wound infection in group B and wascompatible with Razia Iftikar and Sunanda Bharatnur et al study.

It was noted that $3(6 \%)$ patients in group Awhile $13(26 \%)$ patients in group B were febrile in thepostoperative period and it was compatible with PradeepKumar Garg et al.

In group A one patient developedUTI and one patient had RTI during postoperative periodand was compatible with Razia Iftikar and SunandaBharatnur et al study.

One patient of group A was readmitted following complaints of vaginal discharge onher first follow up visit. In the group B, $3(6 \%)$ patientshad UTI, $4(8 \%)$ had RTI and $3(6 \%)$ had paralytic ileusin the postoperative period. No case of paralytic ileus wasreported in NDVH group. One patient in group B wasadmitted with complaints of vaginal bleeding. The pelvicultrasound showed a vaginal vault haematoma of size $3 \times 3 \mathrm{~cm}$ which was managed conservatively and one patient ingroup $\mathrm{B}$ was admitted with complaints of vaginaldischarge and was compatible with Iftikar R et al andBharatnur S study.

\section{CONCLUSION}

From the present study, it was concluded that NDVH isassociated with less blood loss during surgery, quickerrecovery, and early mobilization, less operative and lesspostoperative morbidity when compared to TAH.

Minimal intraoperative manipulation and the avoidanceof an abdominal wound is a remarkable advantage ofNDVH especially for obese, elderly and medicallydebilitated patients. Length of hospita stay issignificantly less for NDVH when compared to TAH.

$\mathrm{NDVH}$ is a less invasive technique with shorter hospitalstay and faster convalescence.

\section{REFERENCES}

1. Alokananda R, Luna P, Roshan B, Rashmi C. Non descent vaginal hysterectomy: A constantly improving surgical art. J Obstet Gynaecol. 2011;61:182-8.

2. Bandyopadhyay S, Pal M. Non-descent vaginal hysterectomy-Analysis of 100 cases. Asian J Medical Science. 2012;3:1-5

3. Bhandra B, Choudhury AP, Nupur AJN. Non descent vaginal hysterectomy: Persona experience in 158 cases. J Med Sci. 2011;4:23-7.

4. Bharatnur S. Comparative study of abdominal versus vaginal hysterectomy in nondescent cases. Internet J Gynaecology and Obstetrics. 2010;15.

5. Choosing the route of hysterectomy for benign disease. ACOG Committee Opinion No. 444. American College of obstetricians and gynaecologists. Obstet Gynecol. 2009;114(5): 1156-8

6. De Frances CJ, Hall MJ. 2005 National Hospital Discharge Survey. Adv Data 2007;(385):1-19.

7. Garg P, Malhotra N, Deka D. Vaginal approach for hysterectomy in benign conditions of the uterus at a rural health setting. Obstet Gynaecol Today. 2003;520-2.

8. Harris WJ. Early Complications of Abdominal and Vaginal hysterectomy. Obste Gynaecol Surv. 1995; 50:795-805.

9. Iftikhar R. Vaginal Hysterectomy is Superior than Abdominal Hysterectomy. J Surgery Pakistan. 2008;13(2):55-8.

10. Kovac SR. Transvaginal Hysterectomy: rationale and surgical approach. ObstetGynaecol. 2004;103:1321-5.

11. McCracken G, Lefebvre GG. Vaginal hysterectomy: Dispelling the myths. JOGS. 2007;29(5):424-7.

12. Rupali D, Shivani A, Bharti MM, Soumendra KS. Non descent vaginal hysterectomy An experience. J Obstet Gynaencol. 2004:54:376-8.

13. Saha R, Shrestha NS, Thapa M, Shrestha J, Bairacharya J, Padhye SM. Non-descent Vaginal hysterectomy: Safety and Feasibility. NJOG. 2012;7(2):14-6.

14. Singh KC, Barman SD, Sengupta R. Choice of hysterectomy for benign disease, department of obstetrics and gynaecology, University College of medical sciences, Delhi. J Obstet Gynaecol. 2004;54: 365-70. 